\title{
Prevalence and risk factors for hypothyroidism in Jordanian women: comparison between different reference ranges
}

A. Alkafajei, ${ }^{1}$ Z. Amarin, ${ }^{2}$ W. Alazaizeh, ${ }^{7}$ Y. Khader ${ }^{1}$ and M. Marji ${ }^{3}$



ABSTRACT The aim of this cross-sectional study in Jordan was to estimate the prevalence of hypothyroidism among women during early pregnancy and to assess the association of risk factors with hypothyroidism. According to internationally adopted thyroid stimulating hormone $(\mathrm{TSH})$ and thyroxine $\left(\mathrm{T}_{4}\right)$ pregnancy reference ranges (TSH $\geq 2.6 \mathrm{mIU} / \mathrm{L}$ and $\left.\mathrm{T}_{4} 10.6-20.4 \mathrm{pmol} / \mathrm{L}\right), 67$ of 322 (20.8\%) women were diagnosed with sub-clinical hypothyroidism. When the general laboratory criteria were applied (TSH $\left.\geq 4.6 \mathrm{mIU} / \mathrm{L}_{\text {and }} \mathrm{T}_{4}<10.6 \mathrm{pmol} / \mathrm{L}\right)$ the prevalence dropped to $4.3 \%$. No cases of overt hypothyroidism were diagnosed using either diagnostic criterion. Younger age and being in gestational weeks 1-8 were significant risk factors for hypothyroidism. It is suggested that the reference criteria need revision, and that pathology laboratories should adopt appropriate pregnancyspecific reference intervals.

Prévalence et facteurs de risque d'hypothyroïdie chez des femmes jordaniennes : comparaison entre différentes valeurs de référence

RÉSUMÉ La présente étude transversale en Jordanie visait à estimer la prévalence de l'hypothyroïdie chez des femmes au début de grossesse et à évaluer l'association des facteurs de risque d'une hypothyroïdie. D'après les valeurs de référence adoptées au niveau international pour la thyréostimuline hypophysaire (TSH) et la thyroxine $\left(\mathrm{T}_{4}\right)$ au cours d'une grossesse (TSH $\geq 2,6 \mathrm{mIU} / \mathrm{I}$ et T4 10,6-20,4 pmol/I), 67 femmes sur 322 (20,8 \%) ont été diagnostiquées avec une hypothyroïdie infraclinique. Lorsque les critères généraux de laboratoire ont été appliqués (TSH $\geq 4,6 \mathrm{mIU} / \mathrm{I}$ et T4<10,6 pmol/I), la prévalence a chuté à 4,3\%. Aucun cas d'hypothyroïdie patente n'a été diagnostiqué avec l'un quelconque des critères diagnostiques. Un âge plus jeune et une grossesse d'une à huit semaines représentaient des facteurs de risque significatifs pour une hypothyroïdie. Il est suggéré que les critères de référence soient révisés, et que les laboratoires de pathologie adoptent des intervalles de référence spécifiquement adaptés aux femmes enceintes.

'Department of Public Health and Family Medicine; ${ }^{2}$ Department of Obstetrics and Gynaecology, Faculty of Medicine, Jordan University of Science and Technology, Irbid, Jordan (Correspondence to Z. Amarin: zoamarin@hotmail.com).

${ }^{3}$ Chest Diseases Centre, Ministry of Health, Irbid, Jordan.

Received: 18/03/10; accepted: 23/06/10 


\section{Introduction}

Detection of hypothyroidism early in pregnancy, before 13 weeks of gestation, and applying proper interventions can significantly reduce the possible adverse effects for the mother and fetus [1]. The large number of adverse consequences associated with hypothyroidism during pregnancy has highlighted the need to focus on screening for thyroid abnormalities early in pregnancy. However, there is currently insufficient evidence to justify universal screening of all pregnant women for thyroid abnormalities before and during pregnancy [2].

The clinical features of thyroid dysfunction during pregnancy are difficult to assess because the signs and symptoms may be interpreted as features of normal pregnancy or may be attributed to other medical conditions $[1,3]$. In addition, many hypothyroid women are asymptomatic and may show no signs of the disease [4]. The diagnosis of hypothyroidism can only be confirmed by laboratory tests of thyroid stimulating hormone (TSH) and thyroid hormones thyroxine $\left(\mathrm{T}_{4}\right)$ and triiodothyronine $\left(\mathrm{T}_{3}\right)[5,6]$. However, it is common in clinical practice to find pregnant women with $\mathrm{TSH}, \mathrm{T}_{3}$ and $\mathrm{T}_{4}$ levels outside the reference range and there is a need for further evaluation to clarify the diagnosis and possible treatment [7]. The current practice is to concentrate on case finding among high-risk women, i.e. those with a personal or family history of thyroid abnormalities and a history of pregnancy complications $[7,8]$. Although the highrisk screening approach is not sufficient to pick up all pregnant women with thyroid abnormalities [9], this approach is supported by the American College of Obstetrics and Gynecology, the Endocrine Society, the British Thyroid Association and the American Association of Clinical Endocrinologists [10].

The current study aimed to estimate the prevalence of hypothyroidism in a sample of Jordanian women during early pregnancy and to ascertain the risk factors for hypothyroidism. We also aimed to quantify the sensitivity, specificity and diagnostic predictive values of the symptoms and risk factors according to internationally adopted TSH and $\mathrm{T}_{4}$ reference pregnancy ranges and to consider the applicability of those criteria to the study population.

\section{Methods}

\section{Study design and setting}

This was a descriptive cross-sectional study of pregnant women in their first 13 weeks of pregnancy. The antenatal clinics in 4 teaching health care facilities, based in the city of Irbid in the north of Jordan, were the setting for the study. Two of the 4 teaching health care institutions were primary health care centres, the other 2 were general hospitals. Data collection was carried out between July 2008 and January 2009. Two months were spent at each of the 4 antenatal clinics.

The study was approved by the institutional review board. An informed consent was signed by each woman.

\section{Sample}

In this cross-sectional study, data were collected on patients as they attended each of the 4 antenatal clinics between July 2008 and January 2009. Two months were spent at each of these clinics. The sample size was estimated at 348 pregnant women in early pregnancy with a confidence level of $95 \%$ and power of $80 \%$ [11]. The sampling procedure from the 4 antenatal clinics was proportional to the number of pregnant women attending each of the 4 clinics. A total of 322 women in early pregnancy agreed to participate, a response rate of $92.5 \%$.

\section{Data collection}

The patients were specifically questioned about the presence or absence of common symptoms associated with hypothyroidism included fatigue, weight gain, constipation, dry skin, hair coarseness, depression, brittle nails, decreased mental concentration, forgetfulness, muscle cramps, feeling cold, pale skin, mode swings, reduced appetite, sleep disturbance, reflex delay, headaches, hand tingling, hoarse voice and history of menstrual irregularities.

The patients were interviewed by specialist physicians to collect data on age, education, occupation, gestational age, personal history of thyroid problems, family history of thyroid problems, diabetes mellitus and previous pregnancy complications.

After enrolment of patients, 5-7 $\mathrm{mL}$ of venous blood was drawn by venipuncture into a tube. The contents were homogenized by gentle inversion 5 times. The blood samples were stored in a secure refrigerator $\left(2-8^{\circ} \mathrm{C}\right)$ laboratory testing. TSH and $\mathrm{T}_{4}$ measurements were conducted using an autoanalyser (Immulite 1000-Free $\mathrm{T}_{4}$ ). The principle of the procedure was competitive analogue immunoassay through solid-phase, 2-site chemiluminescent assay. The study used the following internationally advocated pregnancy diagnostic criteria: for subclinical hypothyroidism, TSH level $\geq 2.6 \mathrm{mIU} / \mathrm{L}$ and $\mathrm{T}_{4}$ measurement between 10.6 and $20.4 \mathrm{pmol} / \mathrm{L}$; for overt hypothyroidism, TSH level $>10 \mathrm{mIU} / \mathrm{L}_{\text {and }} \mathrm{T}_{4}$ measurement $<10.6 \mathrm{pmol} / \mathrm{L}[12,13]^{4}$. For comparison, the local laboratory general diagnostic cut-off points were $\geq$ 4.6 for TSH mIU/L and < $10.6 \mathrm{pmol} / \mathrm{L}$ for $\mathrm{T}_{4}$.

\section{Analysis}

SPSS, version 15 was used for statistical analysis. Differences between means were analysed using independent sample $t$-test. Differences in proportions were analysed using the chi-squared test, and $P$-values $<0.05$ were considered statistically significant. 


\section{Results}

Out of 322 women, 67 women were diagnosed to have sub-clinical hypothyroidism at the pregnancy cut-off levels $\left(\mathrm{TSH} \geq 2.6 \mathrm{mIU} / \mathrm{L}\right.$ and $\mathrm{T}_{4} 10.6-20.4$ $\mathrm{pmol} / \mathrm{L}$ ), a prevalence of $20.8 \%$ (95\% CI: 16.6-25.7). None of the women suffered overt hypothyroidism (TSH $\geq 10$ $\mathrm{mIU} / \mathrm{L}_{\text {and }} \mathrm{T}_{4}<10.6 \mathrm{pmol} / \mathrm{L}$ ) (Table 1). At the higher general diagnostic cutoff points $\left(\mathrm{TSH} \geq 4.6 \mathrm{mIU} / 1\right.$ and $\mathrm{T}_{4}<$ $10.6 \mathrm{pmol} / \mathrm{L})$ the prevalence dropped to $4.3 \%$ (95\% CI: 2.4-7.3) (Table 1).

At pregnancy cut-off levels $(\mathrm{TSH} \geq$ $2.6 \mathrm{mIU} / \mathrm{L}$ and $\mathrm{T}_{4} 10.6-20.4 \mathrm{pmol} / \mathrm{L}$ ),

\begin{tabular}{|c|c|c|c|c|c|c|}
\hline \multicolumn{7}{|c|}{$\begin{array}{l}\text { Table } 1 \text { Thyroid stimulating hormone }(\mathrm{TSH}) \text { and thyroxine }\left(\mathrm{T}_{4}\right) \text { measurements } \\
\text { among the total sample of } 322 \text { pregnant women }\end{array}$} \\
\hline \multirow{2}{*}{$\mathrm{T}_{4}$ level $(\mathrm{pmol} / \mathrm{L})$} & \multicolumn{6}{|c|}{ TSH level (mIU/L) } \\
\hline & $<0.49$ & $0.5-2.5$ & $2.6-4.5$ & $4.6-9.9$ & $>10$ & Total \\
\hline $9.1-10.5$ & 0 & 7 & 5 & 1 & 0 & 13 \\
\hline $10.6-20.4$ & 18 & 219 & $53^{\mathrm{a}}$ & $12^{\mathrm{a}}$ & $2^{\mathrm{a}}$ & 304 \\
\hline$>20.5$ & 3 & 2 & 0 & 0 & 0 & 5 \\
\hline Total & 21 & 228 & 58 & 13 & 2 & 322 \\
\hline
\end{tabular}

aIndicates the 67 women meeting the diagnostic criteria for subclinical hypothyroidism.

women aged 15-24 years and women during their first 8 weeks of pregnancy had higher subclinical hypothyroidism prevalence rates compared with women aged $25+$ years and at gestational weeks 9-13 respectively. Other factors such as educational level, occupation, parity, personal or family history of thyroid problems, diabetes mellitus and previous pregnancy complications were not significantly associated with subclinical hypothyroidism (Table 2). Only 23 of

\begin{tabular}{|c|c|c|c|c|c|}
\hline \multirow[t]{2}{*}{ Variable } & \multirow[t]{2}{*}{ Total no. } & \multicolumn{2}{|c|}{ Hypothyroid } & \multirow[t]{2}{*}{ Odds ratio $(95 \% \mathrm{Cl})$} & \multirow[t]{2}{*}{$P$-value } \\
\hline & & No. & $\%$ & & \\
\hline \multicolumn{6}{|c|}{ Age in years $(n=320)$} \\
\hline $15-24$ & 92 & 27 & 29.3 & $2.0(1.10-3.68)$ & \multirow{2}{*}{0.014} \\
\hline $25+$ & 228 & 39 & 17.1 & 1.0 & \\
\hline \multicolumn{6}{|c|}{ Education in years $(n=320)$} \\
\hline$\leq 12$ & 151 & 37 & 24.5 & $1.5(0.85-2.68)$ & \multirow{2}{*}{0.138} \\
\hline $13+$ & 169 & 30 & 17.8 & 1.0 & \\
\hline \multicolumn{6}{|c|}{ Occupation $(n=319)$} \\
\hline Housewife & 207 & 46 & 22.2 & $1.2(0.67-2.30)$ & \multirow{2}{*}{0.467} \\
\hline Working & 112 & 21 & 18.8 & 1.0 & \\
\hline \multicolumn{6}{|c|}{ Parity $(n=322)$} \\
\hline $0-1$ & 170 & 42 & 24.7 & $1.7(0.93-3.01)$ & \multirow{2}{*}{0.068} \\
\hline $2+$ & 152 & 25 & 16.4 & 1.0 & \\
\hline \multicolumn{6}{|c|}{ Gestational weeks $(n=321)$} \\
\hline $1-8$ & 154 & 41 & 26.6 & $2.0(1.10-3.54)$ & \multirow{2}{*}{0.015} \\
\hline $9-13$ & 167 & 26 & 15.6 & 1.0 & \\
\hline \multicolumn{6}{|c|}{ Personal history of thyroid problem $(n=322)$} \\
\hline Yes & 12 & 4 & 33.3 & $2.0(0.48-7.48)$ & \multirow{2}{*}{0.276} \\
\hline No & 310 & 63 & 20.3 & 1.0 & \\
\hline \multicolumn{6}{|c|}{ Family history of thyroid problem $(n=322)$} \\
\hline Yes & 40 & 12 & 30.0 & $1.8(0.79-3.90)$ & \multirow{2}{*}{0.126} \\
\hline No & 282 & 55 & 19.5 & 1.0 & \\
\hline \multicolumn{6}{|c|}{ Diabetes mellitus $(n=321)$} \\
\hline Yes & 10 & 4 & 40.0 & $2.6(0.62-10.9)$ & \multirow{2}{*}{0.133} \\
\hline No & 311 & 63 & 20.3 & 1.0 & \\
\hline \multicolumn{6}{|c|}{ Previous pregnancy complications $(n=322)$} \\
\hline Yes & 149 & 33 & 22.1 & $1.1(0.63-1.98)$ & \multirow{2}{*}{0.674} \\
\hline No & 173 & 35 & 20.2 & 1.0 & \\
\hline
\end{tabular}

$\mathrm{Cl}=$ confidence interval 


\begin{tabular}{|c|c|c|c|c|c|c|}
\hline \multirow[t]{2}{*}{ Symptom } & \multicolumn{2}{|c|}{ Total with symptoms } & \multicolumn{2}{|c|}{$\begin{array}{l}\text { Hypothyroid with } \\
\text { symptoms }\end{array}$} & \multirow[t]{2}{*}{$\begin{array}{c}\text { Specificity } \\
\%\end{array}$} & \multirow{2}{*}{$\begin{array}{c}\text { Positive } \\
\text { predictive value } \\
\%\end{array}$} \\
\hline & No. & $\begin{array}{c}\text { Sensitivity } \\
\%\end{array}$ & No. & $\begin{array}{c}\text { Sensitivity } \\
\%\end{array}$ & & \\
\hline Brittle nails ${ }^{\mathrm{a}}$ & 11 & 3.4 & 2 & 3.0 & 96.5 & 18.2 \\
\hline Reflex delay a & 15 & 4.7 & 6 & 9.0 & 96.5 & 40.0 \\
\hline Hoarse voice $^{a}$ & 18 & 5.6 & 7 & 10.4 & 95.7 & 38.9 \\
\hline Hand tingling ${ }^{\mathrm{a}}$ & 30 & 9.3 & 11 & 16.4 & 92.5 & 36.7 \\
\hline Hair coarseness ${ }^{a}$ & 33 & 10.2 & 13 & 19.4 & 92.2 & 39.4 \\
\hline Menstrual irregularities & 38 & 11.8 & 10 & 14.9 & 89.0 & 26.3 \\
\hline Dry skin & 43 & 13.4 & 10 & 14.9 & 87.1 & 23.3 \\
\hline Decreased concentration & 51 & 15.8 & 12 & 17.9 & 84.7 & 23.5 \\
\hline Muscle cramps & 57 & 17.7 & 13 & 19.4 & 82.7 & 22.8 \\
\hline Pale skin & 59 & 18.3 & 10 & 14.9 & 80.8 & 16.9 \\
\hline Cold sensitivity & 64 & 19.9 & 12 & 17.9 & 79.6 & 18.8 \\
\hline Sleep disturbances & 71 & 22.0 & 19 & 28.4 & 79.6 & 26.8 \\
\hline Weight gain & 66 & 20.5 & 12 & 17.9 & 78.8 & 18.2 \\
\hline Depression & 67 & 20.8 & 12 & 17.9 & 78.4 & 17.9 \\
\hline Forgetfulness & 95 & 29.5 & 18 & 26.9 & 69.8 & 18.9 \\
\hline Constipation & 96 & 29.8 & 18 & 26.9 & 69.4 & 18.8 \\
\hline Mood swings & 100 & 31.1 & 18 & 26.9 & 67.8 & 18.0 \\
\hline Fatigue & 103 & 32.0 & 19 & 28.4 & 67.1 & 18.4 \\
\hline Reduced appetite & 128 & 39.8 & 25 & 37.3 & 59.6 & 24.3 \\
\hline Headaches & 143 & 44.4 & 29 & 43.3 & 55.3 & 20.3 \\
\hline
\end{tabular}

${ }^{a}$ The top 5 symptoms with specificity of more than $92 \%$.

the 67 hypothyroid women had 1 risk factor or more.

At the same pregnancy cut-offs (TSH $\geq 2.6 \mathrm{mIU} / \mathrm{L}_{\text {and }} \mathrm{T}_{4} 10.6-20.4 \mathrm{pmol} / \mathrm{L}$ ), the most common specific symptoms were brittle nails, reflex delay, hoarse voice, hand tingling and hair coarseness (Table 3). All these symptoms had a specificity rate of more than $92 \%$.

\section{Discussion}

The prevalence of subclinical hypothyroidism among pregnant women in this study, according to internationally advocated pregnancy reference ranges for $\mathrm{TSH}$ and $\mathrm{T}_{4}$, was $20.8 \%$. Many studies have shown lower prevalence estimates of hypothyroidism among pregnant women [14-18]. One of the reasons for this discrepancy is thought to be the gestational age at which screening is performed. The women included in this study were exclusively in their first trimester of pregnancy. Serum human chorionic gonadotropin (hCG) hormone peaks at 10 weeks of gestation, and fetal thyroid hormones are not fully functional until the 12th week of gestation, before which the fetus is dependant on the mother's hormones [19]. It is well established that hCG is a putative thyroid stimulator. The thyrotropic activity of hCG in normal pregnant women is, at least in a part, mediated by TSH receptors [20]. An abnormal interaction of hCG and TSH hormones early in pregnancy may be a factor causing different rates of subclinical hypothyroidism in different populations.

A second reason for the high prevalence in this study was perhaps the use of a lower cut-off TSH level. The new diagnostic guidelines recommended for pregnant women in early pregnancy of TSH level $>2.6 \mathrm{mIU} / \mathrm{L}$ permit the inclusion of a wide spectrum of pregnant women. TSH reference levels are still an area of contention in which a set of studies adopted the new recommended TSH range between 2.3-2.8 mIU/L [14], while other studies proposed a higher limit of TSH level early in pregnancy of $>3.0 \mathrm{mIU} / \mathrm{L}$ $[7,9,18,19]$.

In this study, although certain risk factors showed an obvious association with hypothyroidism (younger age and being in gestation weeks 1-8), only a minority of the hypothyroid women exhibited those risk factors. If screening were restricted to those women with risk factors, about two-thirds of those cases would not have been included. 
The list of symptoms for subclinical hypothyroidism reported in the present study was similar to those reported by other studies [21,22]. Five symptoms (hair coarseness, brittle nails, reflex delay, hand tingling and hoarse voice) had a specificity rate of more than $92 \%$. However, it should be noted that the symptoms of hypothyroidism are insidious and can be masked by the hypermetabolic state of pregnancy [4].

Estimates of thyroid hormones by different methods may show discrepancies even in identical samples, as shown by Sapin et al. [23]. Thus, there is a possibility that an erroneous diagnosis of either secondary or central hypothyroidism could be considered, solely as a result of variations in methodology. Furthermore, the reference interval for TSH during the first trimester of pregnancy has been found to differ substantially from that for non-pregnant women [24]. Therefore, we conclude that pathology laboratories should adopt pregnancyspecific reference intervals for thyroid function tests that are appropriate for their populations.

\section{References}

1. Beastall $\mathrm{GH}$ et al. Interpretation of thyroid function tests. UK guidelines for the use of thyroid function tests (updated, 2008). London, British Thyroid Association, 2006.

2. Neale D, Burrow G. Thyroid disease in pregnancy. Obstetrics and Gynecology Clinics of North America, 2004, 31:893-895.

3. LeBeau SO, Mandel SJ. Thyroid disorders during pregnancy. Endocrinology and Metabolism Clinics of North America, 2006, 35:117-136.

4. Wier FA, Farley CL. Clinical controversies in screening women for thyroid disorders during pregnancy. Journal of Midwifery and Women's Health, 2006, 51:152-158.

5. Dufour DR. Laboratory tests of thyroid function, uses and limitations. Endocrinology and Metabolism Clinics of North America, 2007, 36:579-594.

6. American Association of Clinical Endocrinologists medical guidelines for clinical practice for the evaluation and treatment of hyperthyroidism and hypothyroidism. Endocrine Practice, 2002, 8:457-469.

7. Surks MI et al. Sub-clinical thyroid disease: scientific review and guidelines for diagnosis and management. Journal of the American Medical Association, 2004, 291:228-238.

8. Vaidya B et al. Detection of thyroid dysfunction in early pregnancy: Universal screening or targeted high-risk case finding? Journal of Clinical Endocrinology and Metabolism, 2007, 92:203-207.

9. Stagnaro-Green A. Can a high-risk case-finding approach identify all women with thyroid dysfunction during pregnancy? Nature Clinical Practice. Endocrinology and Metabolism, 2007, 3:216-217.

10. Vaidya B et al. Screening for thyroid disease in pregnancy: an audit. Clinical Medicine (London, England), 2002, 2:599-600.

11. Fleiss JL. Statistical methods for rates and proportions, 2nd ed. New York John Wiley, 1981:38-45.

12. Levenson D. Thyroid disorders in pregnancy, new guidelines recommend against universal screening, suggest a new TSH reference limit. Clinical Laboratory News, 2007, 33(9).

13. Soldin OP. Thyroid function testing in pregnancy and thyroid disease: trimester-specific reference intervals. Therapeutic Drug Monitoring, 2006, 28:8-11.
14. Casey BM et al. Sub-clinical hypothyroidism and pregnancy outcomes. Obstetrics and Gynecology, 2005, 105:239-245.

15. Glinoer $\mathrm{D}$. The regulation of thyroid function in pregnancy: pathways of endocrine adaptation from physiology to pathology. Endocrine Reviews, 1997, 18:404-433.

16. Shan ZY et al. A study for maternal thyroid hormone deficiency during the first half of pregnancy in China. European Journal of Clinical Investigation, 2009, 39:37-42.

17. Aoki $\mathrm{Y}$ et al. Serum TSH and total $\mathrm{T}_{4}$ in the United States population and their association with participant characteristics: National Health and Nutrition Examination Survey (NHANES 1999-2002). Thyroid, 2007, 17:1211-1223.

18. Kennedy RL, Malabu UH, Porter D. Assessment of thyroid function during pregnancy: first-trimester (weeks 9-13) reference intervals derived from Western Australian women. Medical Journal of Australia, 2009, 190:219-220.

19. Negro R et al. Levothyroxine treatment in euthyroid pregnant women with autoimmune thyroid disease: effects on obstetrical complications. Journal of Clinical Endocrinology and Metabolism, 2006, 91:2587-2591.

20. Hoermann R et al. Interaction of human chorionic gonadotropin (hCG) and asialo-hCG with recombinant human thyrotropin receptor. Journal of Clinical Endocrinology and Metabolism, 1994, 78:933-938

21. Matalon $\mathrm{S}$ et al. Relationship of treated maternal hypothyroidism and perinatal outcome. Journal of Reproductive Medicine, 2006, 51:59-63.

22. Roberts CG, Ladenson PW. Hypothyroidism. Lancet, 2004, 363:793-803.

23. Sapin R et al. Intermethod discordant free thyroxine measurements in bone marrow-transplanted patients. Clinical Chemistry, 2000, 46:418-422.

24. Gilbert RM et al. Assessment of thyroid function during pregnancy: first-trimester (weeks 9-13) reference intervals derived from Western Australian women. Medical Journal of Australia, 2008, 189:250-253. 